\title{
Law in the Face of Disruptive Technology, An Introduction
}

\author{
Marta Katarzyna KOŁACZ and Alberto QUINTAVALLA*
}

Disruptive innovations provoke controversial political responses. They affect established business models and settled social norms. The question faced by society is whether and how to regulate innovation. The question grows more pressing as innovation grows more rapid. In pre-antiquity, innovation similarly engendered major changes to society. For example, improvements in irrigation technology caused whole populations to migrate to large cities in Ancient Egypt. The pace of social change was, however, comparatively slow, as was the diffusion of technology. It could take hundreds of years for a new technology - say an improvement in agriculture - to spread. The resultant social pressures, even if significant, did not require wide-scale interventions into the economy. Indeed, they did not even require the formation of government.

But we now live in a time of rapid change: technologies are developing fast, digital economies are emerging and markets are growing more integrated. Netflix rendered DVDs obsolete. What Netflix did to DVDs is what Uber will do to taxis. Incipient technologies, such as nanorobotics and genetic engineering, are widely forecast to revolutionise our lives. The impact of all those technologies is unknown and to some extent unknowable. In the context of that uncertainty, the role of law, legislators, courts and regulators is paramount.

At its core, the concept of "disruptive innovation" refers to business models or technologies that challenge incumbent businesses, successfully targeting overlooked market segments. In common parlance, the term has begun to encompass all technological and business breakthroughs which reshape markets. Such innovations lead to a need to reassess the effectiveness of the existing legal frameworks and, if appropriate, to reform the law.

The legislator faces a difficult choice: either let judges decide according to the current law, or promulgate new legislation. Although these two options may seem mutually exclusive, they also overlap. Thus, the legislator may decide to let judges decide cases according to pre-existing rules at first. Once the new dynamics are fully understood, new statutes may be drafted or old ones amended.

* Erasmus University Rotterdam, email addresses kolacz@law.eur.nl and quintavalla@law.eur.nl. The authors would like to thank Menelaos Markakis and Elena Kantorowicz-Reznichenko for previous insights on the overall idea. Also, we would like to thank the European Journal of Risk Regulation and, in particular, its Managing Editor Cliff Wirajendi for his prompt and steady support. 
This Special Issue tries to draw a picture of where the regulatory discussions of disruptive innovation stand. The general problem at stake is the choice of regulation to deal with a rapidly changing environment. More precisely, there is a choice between using old laws and writing new ones. Should the law change to reflect progress in common conceptions of morality, technology, or economic conditions? Or should the law regard the newly developed issues as contemporary manifestations of old legal categories? The central purpose of this Special Issue is to offer answers to the following questions.

1. Do disruptive innovations create a need for new norms?

2. What legal instruments can tackle the issues put forward by these innovations?

3. Are pre-existing general principles enough to guarantee legal certainty in an age of innovation?

Whilst Ronald Dworkin may have preferred to see Hercules search for the right answer amongst the law reports, Jeremy Bentham may have chosen to begin drafting a new statute. We consider the relative efficaciousness of these approaches here, in the hope that our contributions may serve as a useful manual to lawyers faced with disruptive innovations. The individual insights shed more light on the topic, hopefully leading to a more systematic view on the viable regulatory approaches. The selected contributions aim to provide guidance as to how regulators can respond to disruptive innovations.

The Special Issue starts with the contribution of Kołacz, Quintavalla and Yalnazov, who discuss disruptive innovations. They distinguish between risky and uncertain innovations, using autonomous cars and 3D printing as examples. The primary concern of the paper is the cost of acquiring information by judges and legislators in the process of regulating new technologies. The authors argue that the judiciary is better suited to the regulation of risky technologies, whereas uncertain technologies should be regulated through statute. Their contribution also provides a general framework for further papers focusing solely on specific instances of disruptive technologies.

The aggregation of information necessary to make regulatory decisions about new technologies is further tackled in Buiten's submission. Buiten discusses the issue in the context of Artificial Intelligence and its transparency. She argues that AI transparency requires focusing on the concrete risks and biases of its underlying technology: machinelearning algorithms. Any transparency requirement for algorithms should result in explanations of biases that algorithms may present. These have to be simultaneously comprehensible to prospective recipients and technically feasible to producers. AI transparency would then enable judges to adjudicate on the risks of AI technology.

Thereafter, the Special Issue focuses on the tension between existing legal rules applied to new circumstances and new legislative interventions tailored to specific innovations. This is discussed in the context of Airbnb, 3D printing and genetic engineering.

Wells' paper focuses on Airbnb, which has led to a rise in the use of residential properties as short-term lets. Wells considers the social efficiency of the use of the public town planning system and alternative private law systems to regulate spill-over amenity 
effects on neighbouring properties. He argues that in the case of short-term lets, the private law system entails relatively low transaction costs. The courts, properly equipped with private information from litigants and public information from development plans, are well placed to regulate Airbnb.

The discussion on Airbnb is followed by a paper by Heine and Li, who circle on the influence of 3D printing on product liability law. Heine and Li ask why incumbent product liability law does not incentivise optimal deterrence to harmful 3D printed products. They conclude that new business models associated with $3 \mathrm{D}$ printing are not dominated by economies of scale. This results in reduced information production. The scarcity of information prevents courts from being able to identify tortfeasors.

The Special Issue concludes with Lansink's contribution. Lansink discusses the legal aspects of technological innovation and animal use. She shows that genetic engineering and cloning might render EU and UK animal protection laws ineffective. She seeks a solution in the established concept of dignity, proving the durability of pre-existing legal categories.

Whether disruptive innovations create a need for new norms depends on the regulator's understanding of the technologies, as well as on the ability of jurists to position new social phenomena within old legal categories. In other words, as our understanding of the social impact of new technology improves, so do our chances of regulating innovations adequately. We are reasonably well-informed about autonomous cars, genetic engineering, and AirBnB, and less well-informed about 3D printing. We can regulate some things well, but not others. As a result, our system of regulation is imperfect. We are hopeful that the papers in this Special Issue are a first step in remedying its inadequacies. 